\title{
Latent, early or late HHV-6B expression in adult mesial temporal lobe epilepsy: Association of virus life cycle with inflammatory cytokinesin brain tissue and cerebral spinal fluid
}

\author{
Jiaqi Wang \\ West China Hospital of Sichuan University \\ Hong-Yu Yang \\ University of Electronic Science and Technology of China Hospital \\ Xue Shao \\ Biotheus Inc \\ Xin-Yue Jiang \\ West China Hospital of Sichuan University囚Chengdu Second People's Hospital \\ Jinmei Li ( $\nabla$ lijinmei@wchscu.cn ) \\ West China Hospital of Sichuan University
}

\section{Research Article}

Keywords: Human herpes virus-6B, mesial temporal lobe epilepsy, inflammatory cytokines, polymerase chain reaction, immunohistochemistry

Posted Date: February 9th, 2022

DOI: https://doi.org/10.21203/rs.3.rs-1302425/v1

License: (c) (i) This work is licensed under a Creative Commons Attribution 4.0 International License.

Read Full License 


\section{Abstract}

Background: Human herpes virus-6B (HHV-6B) was suggested as an important etiologic factor of mesial temporal lobe epilepsy, while the mechanism is still unknown. Here, we aimed to analyze antigens representing latent, early and late HHV-6B infection and the association with inflammatory cytokines in brain tissue and cerebral spinal fluid (CSF) from MTLE patients with HHV-6B-positivity.

Results: Nested polymerase chain reaction (nPCR) in brain tissue revealed HHV-6B DNA in 19 of 49 MTLE patients $(39 \%)$ and 1 of 19 controls $(5 \%)(P<0.001)$, but not in CSF. ICH showed HHV-6B early antigen (P41) positivity in 3 patients (6\%), late antigen (gp116/54/64) positivity in 5 patients (10\%), latent antigen (U94) positivity in 8 patients (16\%), and multiple antigen (early and late or/and latent) positivity in 9 patients $(18 \%)$. None of these HHV-6B related proteins were found positive in control brain tissue. PCR revealed significant up-regulation of IL-1a, IL-2 and IL-7 mRNA levels in brain tissue from MTLE patients with different virus state. Suspension bead array in CSF confirmed significant up-regulation of IL-1a and IL-7 protein expression.

Conclusions: Our finding suggests HHV-6B is a common etiologic agent of MTLE. Different virus life cycle may play an important modifying role in inflammatory biology that warrants further investigation. Though virus DNA is difficult detected in CSF, up-regulation of IL-1a and IL-7 in CSF indicates the two cytokines may be taken as indirect biomarker of HHV-6B infection.

\section{Introduction}

Mesial temporal lobe epilepsy (MTLE), is the most common form of chronic epilepsy characterized by mesial temporal sclerosis (MTS), and its most common form of pathology is hippocampal sclerosis (HS) $[1,2]$. In recent years, Human herpes virus-6B (HHV-6B)was suggested as a possible etiologic candidate of MTLE because it has been detected in brain tissue and cerebral spinal fluid (CSF) of patients[3-8]. HHV-6B can establish latency thougout life after primay infection and reactivate in the host. It indicates HHV-6B may play an epileptogenitic role in that may affect chronic course of MTLE, particularly associated with HS and history of febric convulsions $[9,10]$. We noted that in several previous studies DNA detection ranged from $9 \%$ to $69 \%$ while protein detection in $50 \%$ to $69 \%$ MTLE patients[ $[4-8,11,12]$.

HHV-6B DNA and protein level may respond to different states of the virus such as latency, replication or reactivation, acute or chronic infection. One study revealed high HHV-6 DNA detection (55.6\%) but not protein $(2.6 \%)$ in brain tissue from MTLE patients[13]. The viral DNA and protein did not match each other, which indicates that the virus may periodically reactivate. However, It is not known whether these observations represent latent, early or late HHV-6 expression, since there has been no larger scale analysis of HHV-6 latent or active expression published to date.

It may indicate different virus state such as latency, replication or reactivation may be involved in MTLE chronic process. In this study, we try to differentiate the different viral states in MTLE. We also attempted 
to detect HHV-6B DNA in cerebrospinal fluid in MTLE patients which has not been reported previously to our knowledge.

Cytokines are soluble proteins acting as immune mediators in inflammatory process. Previous studies suggest that HHV-6B can infect astrocytes and oligodendrocytes[14] and promote the expression of various pro-inflammatory factors.up-regulation of inflammatory cytokines as IL-6, IL-8, IL-1 $\beta$, IL-10, IL-11 may be involved in the procession of acute or chronic HHV-6 infection.[15-18]The data suggest that HHV$6 \mathrm{~B}$ triggers immune modulatory factors. However, there is not known whether inflammatory cytokines is associated with different viral states. To further elucidate a role of cytokines in HHV-6B infection, PCR and suspension bead array were performed.

\section{Materials And Methods}

\section{Subjects}

49 patients were from the Department of Neurosurgery, West China Hospital. Pre-surgery evaluation of each case included video electronencephalography (VEEG) monitoring, brain magnetic resonance imaging (MRI), positron emission tomography(PET), and/or Depth electrodes. All surgical samples were sliced into small pieces and preserved in nitrogen and $4 \%$ formalin respectively.MTLE was diagnosed according to 2011 International League Against Epilepsy (ILAE) Classification[19]. Lumbar puncture was done before surgery in all patients.

Non-epilepsy control samples were obtained from 19 patients who had serious brain trauma or a vascular event and underwent a neurosurgical procedure. All samples (controls and cases) comprised neocortical tissue and/or hippocampal tissue.CSF of controls was obtained from patients with chronic headache whose diagnosis ruled out CNS infection and tumor. The study was approved by the Ethics Committee of the West China Hospital of Sichuan University. Informed consents were obtained from patients or their direct relatives for the use of brain tissue and CSF. Control brain samples were only included if histological examination was normal.

\section{Nested PCR and RT-qPCR for virus DNA in brain tissue}

DNA was extracted from every sample using a DNA purification kit (Qiagen, Germany). DNA amplification was performed using nested primers specific for highly conserved sequences in viral genome. The total reaction volume of external amplification was comprised with $4 \mu \mathrm{L}$ of $5 \times \mathrm{PCR}$ buffer, $2 \mathrm{ul}$ of $20 \%$ Glycerol, $2 \mathrm{ul}$ of $10 \times \mathrm{dNTP} \otimes 2 \mathrm{mM} \otimes, 0.5 \mathrm{ul}$ of forward primer (10uM), $0.5 \mathrm{ul}$ of reverse primer (10uM), $1 \mathrm{ul}$ of DNA sample, $0.5 \mathrm{ul}$ of HS-Taq $(5 \mathrm{U} / \mu \mathrm{L}), 9.5 \mathrm{ul}$ of $\mathrm{ddH}_{2} \mathrm{O}$. DNA was amplified followed by 20 cycles of PCR under the following conditions: $94{ }^{\circ} \mathrm{C}$ for $5 \mathrm{~min}, 95^{\circ} \mathrm{C}$ for $30 \mathrm{~s}, 58^{\circ} \mathrm{C}$ for $30 \mathrm{~s}, 72{ }^{\circ} \mathrm{C}$ for $45 \mathrm{~s}$, and $72{ }^{\circ} \mathrm{C}$ for 2 min. Then a total of $2 \mu \mathrm{L}$ of PCR products was amplified using theinternal primers according above process. A total of $10 \mu \mathrm{L}$ of the final PCR product was subjected to $1.5 \%$ agarose gel electrophoresis to determine the molecular weight for distinguishing HHV-6B positive samples from negative samples. 
Then viral DNA in HHV-6B-positive samples werequantified by TaqMan PCR with internal primer. The total reaction volume of internal amplification comprised $3 \mu \mathrm{L}$ of $10 \times$ buffer $\left(\mathrm{Mg}^{2+}\right.$ free), $3 \mu \mathrm{L}$ of $\mathrm{MgCl}_{2}(25$ $\mathrm{mM}), 0.36 \mu \mathrm{L}$ of dNTP $(25 \mathrm{mM}), 1 \mu \mathrm{L}$ of forward primer $(10 \mu \mathrm{M}), 1 \mu \mathrm{L}$ of reverse primer $(10 \mu \mathrm{M}), 0.6 \mu \mathrm{L}$ of Taqman probe $(10 \mu \mathrm{M}), 0.3 \mu \mathrm{L}$ of Taq enzyme $(5 \mathrm{U} / \mu \mathrm{L}), 17.74 \mu \mathrm{L}$ of $\mathrm{ddH}_{2} \mathrm{O}$, and $3 \mu \mathrm{L}$ of DNA sample. It was amplified followed by 45 cycles of PCR under the following conditions: $94{ }^{\circ} \mathrm{C}$ for $2 \mathrm{~min}, 94^{\circ} \mathrm{C}$ for 15 $\mathrm{s}, 60^{\circ} \mathrm{C}$ for $30 \mathrm{~s}$.Vascular endothelial growth factor (VEGF) was used as a control marker (two copies of VEGF is considered equal 1 cell). The viral DNA was expressed as viral copies $/ 1 \times 10^{6}$ cells after the cycle threshold (Ct) of the virus was adjusted. All primers were showed in Supplemental Table 1.

\section{Immunohistochemistry for HHV-6B in brain tissue}

Samples from the cases were investigated for HHV-6B infection using Immunohistochemistry(IHC) described in the previous study[20]. Specimens were deparaffinized and dehydrated in graded alcohol series, washed with PBS, and incubated for $1 \mathrm{~h}$ with blocking buffer (3\% FCS, $1 \%$ goat serum, $0.1 \%$ Triton $\mathrm{X}-100$ in TBS), overnight with primary antibodies, and then incubated with secondary antibodies for $1 \mathrm{~h}$ at room temperature. The primary antibodies include HHV-6A/B specific Gp116/64/54 and P41 and HHV-6B specific U94 (providedby the HHV-6 Foundation, dilute concentration was 1:400, 1:500, 1:500, respectively). Anti-NeuN (Rabbit antibody, 1:500, Abcam), anti-glial fibrillary acidic protein (GFAP, Rabbit antibody, 1:500, Abcam),Positive control was SUP-T1 T-cell line containing HHV-6B viral genome (providedby the HHV-6 Foundation). Immunoreactivity was observed under a PM20 microscope (Olympus, Japan).

\section{Real-time quantitative PCR for Inflammatory cytokines in brain tissue}

RNA in patient samples was purified with RNA purification kit (QIAGEN) and spectroscopy confirmed that the RNA 260/280 ration was >1.8. RNA was then reverse transcribed using a Bio-Rad iScript Kit. The cDNA was quantified by qPCR using SYBR Green (Bio-Rad).Each reaction was run in triplicate and analyzed following the $\Delta \Delta \mathrm{Ct}$ method as previously described using actin as a normalization control.

\section{Nested PCR for virus DNA in CSF}

CSF samples were completely thawed and centrifuged at $3000 \mathrm{r} / \mathrm{min}$ for $10 \mathrm{~min}$ before testing. DNA extraction and amplification were performed according method described above.

\section{Suspension bead array for cytokines in csf}

CSF cytokine protein level was detected by using MILLIPLEX MAP (EMD Millipore Corp, Missouri, USA). Twelve cytokines including TGF- $a$, IL-10, IL-1RA, IL-9, IL-3, IL-4, IL-5, IL-6, IL-7, IL-8, TNF- $a$ and VEGF were detected. The procedure was performed according to the manufacture's protocol for Cytokine kit, assayed in triplicate, and read on a Molecular microplate reader at 450nm (Menlo Park, CA). Standard curves and individual well concentrations were determined using the Softmax 2.34 software (Molecular Devices, Menlo Park, CA). Data analysis was performed using the MasterPlex QT 1.0 system (MiraiBio, Alameda, 
CA). A five-parameter regression formula was used to calculate the sample concentrations from the standard curves. All 96 samples were analyzed with the LINCOplex kit (Linco Research Inc).

\section{Statistical analyses}

SPSS 19.0 software for Windows was used (Chicago, USA). The Independent-sample t-test was used to compare differences among continuous variables of MTLE patients and control individuals. The chisquare $\left(\chi^{2}\right)$ test with Fisher's exact was used to compare categorical parameters among groups. MLTE cases were categorized into subgroups according to IHC results for HHV-6B. Univariate analysis was used for measuring the association of HHV-6 viral phase and clinical manifestations. Two-tailed tests were used and a $\mathrm{P}<0.05$ was considered statistically significant

\section{Results}

\section{Clinical data and pathological findings}

Of the 49 patients with epilepsy, 20 (41\%) were male. Mean age was 26.7 years (standard deviation [SD] 11.1, range 15 to 55). Epilepsy duration ranged from 3 to 32 years (mean 10.4, SD 6.5). Clinical and pathological findings of the 49 cases are provided in Table 1.9 of the 19 controls were male (47\%). Mean age was 32.52 years (SD 8.1, range 15 to 61). 12 cases had traumatic injuries and the remaining 7 had cerebral hemorrhage or infarction. Clinical and pathological findings of the 19 cases are provided in Table 2. The resected tissues included temporal neocortex ( 11 cases) and hippocampus (8 cases). CSF was obtained from 15 patients with headache. Nine of them were male (60\%). Mean age was 45.1 years (SD 7.4 , range 23 to 54$)$.

\section{HHV-6B DNA load}

HHV-6B DNA was detected in brain tissue from 19 MTLE patients and 1 controls by nested PCR $(p=0.049)$. HHV-6B sequence was not detected in any csf samples. The PCR amplification products from HHV-6B-positive DNA samples are shown in Fig 1.

\section{Pathological finding and detection of HHV-6B latent, early and late antigens by IHC.}

IHC revealed multiple antibodies immunoreactivity including P41, Gp116/65/64 and/or U94 in 9 MTLE patients. Single early, late and latent antibody positivity was shown in 3,5 and 8 cases, respectively. HHV$6 \mathrm{~B}$ latent antibody positivity was presented in 3 control cases. Staining for HHV-6B antibodies were observed to be distributed mainly around or in the nucleus of cells that resembled astrocytes. Antibody staining in sample of the control group was relatively faint. Fig 2 and Fig 3 shows the pathological finding and immunohisitochemical results.

The DNA load in the groups of early, late multiple antibodies immunoreactivitywas higher than that of the group with latent antigen. Fig 4 shows the results of the relationship of HHV-6 immunoreactivity and viral DNA load. 


\section{Analysis of cytokinem RNA level in brain tissue and protein level in csf}

In brain tissue, detection of cytokine mRNA levels by PCR revealed significant up-regulation of IL-1a, IL-1 3 , IL-2 and IL-7 mRNA levels in MTLE patients with HHV-6B-positivity compared to MTLE patients with HHV$6 \mathrm{~B}$-negativity orthe control tissues $(\mathrm{P}<0.01)$. The post hoc tests result of cytokines mRNA levels in brain tissuewas showed in Fig 5.In CSF, detection of cytokine protein levels bysuspension bead arrayrevealed that significantly upregulation of IL-1 aandIL-7 in MTLE patients with HHV-6B-positivity compared to HHV$6 \mathrm{~B}$-negativity and the control $(P<0.01)$. The post hoc tests result of cytokines mRNA levels in CSF was showed in Fig 6.

\section{Dissussion}

$\mathrm{HHV}-6 \mathrm{~B}$ is considered as an etiologic agent involved in etiopathogenesis of MTLE[10, 21, 22]. Our finding confirmed that HHV-6B is a potential etiologic agent involved in etiopathogenesis of MTLE. The data showed higher HHV-6B DNA (19 cases, 39\%) and protein (25 cases, 51\%) expression. Previous studies that showed $9-69 \%$ DNA and $50-69 \%$ protein positivity in MTLE patients. A meta analysis which mergers 10 researchs in recent years about MTLE and HHV-6b infection shows that the HHV-6 DNA detection ratio in MTLE patients $(126 / 645,19.5 \%)$ is higher than the control group (14/136,10.3\%) (pष0.05)[9]. No HHV$6 \mathrm{~A}$ has been detected[21]. The discrepancy of detection in the study is potentially not only due to sample size, race and region etc, but also involve viral life cycle and technology sensitivity.

HHV-6 like other herpesviruses causes both productive and latent infections. In productive infection, the infected cells express most if not all viral antigens. P41, an early antigen yielding proteins of 41Da[15, 23, 24],is a major DNA-binding protein and processivity factor stimulating viral replication. It frequently appears 12 to 18 hours after infection before viral DNA synthesis[25, 26]. The expression of P41 plays an important role in viral propagation and active replication. The late membrane antigen complex Gp116/64/54 against glycoprotein B is a late protein which is useful in identifying reactivation of HHV$6 \mathrm{~B}[27]$. In our finding, the regulatory immediate early antigen (P41) and late antigens (GP116) are expressed alone or together, and the later is more common $(\mathrm{P}<0.05)$. The detection of both $\mathrm{P} 41$ and late gp116/64/54 antigens are suggestive of active virus infection. However, we did not found lymphocytic infiltration in brain samples. It suggests neuro-immune defense system is not activated and HHV-6 may be involved in the pathogenic process of MTLE through inflammatory mediators such as chemokinesorcytokines. It may permit viral reactivation without severe inflammatory response.

HHV- 6 is the only herpesvirus encoding a rep-like function, while latency is a general feature of this family of viruses. HHV- 6 integrates the genome into the telomere sequence of host chromosomes, and U94 may play a role in this process. Previous research showed that U94 is expressed in the incubation period, and has the activities of DNA binding protein, adenosine triphosphate enzyme, exonuclease and helicase, and regulates viral gene expression and enables the establishment and/or maintenance of latent infection in vitro[28, 29]. HHV-6 is the only human beta herpes virus endoding U94 protein. In our study, U94 antigen, which is specific for HHV-6B, was detected in $11(22 \%)$ cases, with alone $8(16 \%)$ and co-expressed with 
productive antigens (6\%). The data demonstrate that the latent state of HHV-6B infection is common in MTLE. U94-positivity was found in temporal lobe tissue and hippocampus from six MTLE patients who had only with U94-immunostaining-positivity without viral DNA detection. This suggests that the levels of viral DNA remain below the limit of detection. These findings are consistent with the hypothesis that U94 antigen may regulate the viral life cycle by restricting beta herpes virus replication[30].It also suggests that unlike the state of persistent viral replication, only small-amount viral genes are expressed in the latent state. In previous studies, available evidence showed only latency-associated transcripts are detectable in the case of HSV during viral latency[28]. It indicates that U94 may be considered as a potential hallmark of HHV-6B latency. But more research is needed to discover U94's role in HHV integration and latency process. Previous study showed that. We observed that U94 co-expressed with productive antigens in three cases, which suggests that the virus may be reactivated during latent infection or in the state of latency and reactivation at the same time[31]. It may be associated with different viral life cycle of virues distributed in different regions of hippocampus. However, there have been recent findings that $\mathrm{U} 94$ is not required for HHV-6A integration[32]. Further studies are needed to explore the role of U94 and the mechanisms of HHV-6 reactivation in these processes.

HHV- 6 is a low copy number virus compared to HSV-1, and is highly cell associated. Encephalitis patients can have very high HHV- 6 viral load in the brain tissue with negligible levels in the CSF and plasma[33].HHV-6 DNA can be detected inthe CSF in patients with the acute phase of HHV-6 encephalopathy $(7 / 13,53.8 \%)$, but the level is very low compared to in serum [16].In HHV-6A was be detected in the CSF which was collected in a subset of MS patients, but only during relapse and not during remission[34-38]. As expected, we did not detect viral DNA in any CSF samples. It may be that HHV6 DNA can be immediately after a seizure, and our patients were not acutely ill. Since the virus spreads cell-to-cell and since HHV-6B does not cause cell death during active latency, HHV-6B DNA from lysed cells, if any,fell below our limit of detection or technique sensitivity. It suggests that the DNA level of HHV$6 B$ in CSF from MTLE patients with HHV-6B-positivity is different with that of in acute HHV-6 encephalitis. We were not able to use HHV-6B DNA in CSF as biomarker of HHV-6B infection in brain tissues, others may be more successful using ultra-sensitive methods such as high speed centrifugeto concentrate a large volume of material.

We study cytokine changes in HHV-6B infection in MTLE patients at different stages . There are few study on cytokines in MTLE patients with HHV-6B-positivity.No typical inflammatory infiltration changes were found in the pathological specimens of TLE patients, and searching for inflammatory immune mediators may help to find the relationship between HHV infection and the pathogenesis of MTLE. Our data showed up-regulated mRNA of IL-1a, IL-2 and IL-7 in brain tissue and up-regulation of IL-1a and IL-7 protein in CSF from MTLE patients with latent, early, late and multiple antigen positivity for HHV-6. The distribution of these cytokines differed between brain and CSF. The up-regulation of cytokines is not completely equivalent to the results of previous studies on HHV-6 encephalopathy that showed upregulated IL-8 and IL-6 $[24,36]$. It suggests different immune-mediated mechanism between HHV-6 encephalopathy and MTLE with HHV-6 infection. IL-1a and IL-7 was upregulated significantly in early antigen expression compared to other samples of latency, late or multiple forms of HHV-6B infection. It 
indicates that the two cytokines may be associated with the pathogenesis of the MTLE with HHV-6B infection and could be considered as indirectly biomarkers of HHV-6 re-activation.

A major shortcoming of our study is that we could not certain whether these antigens mark the same infected glial cells because all HHV-6 antibodies are mouse origin. The preferential expression of both early and late viral antigens may be related to the productive state of the virus and the differentiation state of the transformed cell. We found that the distribution of early, latancy and late antigens was preferentially localized in different cells, however, we could not speculate whether it was related to cellspecific infections in different viral cycle. Larger studies or basic animal studies are needed to help clarify whether cytokine expression is affected by different HHV infection states $\square$ time of seizure onset $\square$ other viral infection factorsand etc. These studies may provide insights for early antiviral and future development and application of anti-inflammatory drugs.

\section{Conclusion}

In summary, our finding suggests HHV-6B is a common etiologic agent of MTLE. Cytokines like IL-1a, IL-2 and IL-7 are activated in brain tissue. Up-regulation of IL-1a and IL7 in CSF indicates the two cytokines may be taken as indirect biomarker of viral infection. The role of HHV-6 in regulating the expression of cytokines may be important to the understanding of the pathogenesis and progression of chronic MTLE. Further work is needed to elucidate the function of HHV-6 in MTLE.

\section{Declarations}

\section{Ethics approval and consent to participate}

Informed consent was obtained from all individual participants included in the study. All experimental protocols and methods were approved by the Ethical Review Board of West China Hospital, Sichuan University approved the study (No 2019449).

\section{Consent for publication}

Not applicable.

\section{Availability of data and materials}

The datasets used and/or analysed during the current study available from the corresponding author on reasonable request

\section{Declaration of interests}

We declare no competing interests.

\section{Funding}


The work was supported by grants from the Science \& Technology Department of Sichuan Province (No.2019YFH0145)

\section{Authors' contributions}

The work presented here was carried out in collaboration between all authors. J-mL, J-qW and H-yY defined the research theme and designed the methods and experiments. H-yY and X-S gathered and prepared the human tissues for the experiments. J-qW , H-yY and X-yJ was involved in drafting, reviewing, and writing the final manuscript. J-qW , X-yJ, H-yY and X-S was responsible for the data. J-mL was responsible for the intellectual content of the report. All authors approved the final manuscript.

\section{Acknowledgements}

Not applicable.

\section{Authors' information}

${ }^{1}$ Department of Neurology, West China Hospital, Sichuan University, Chengdu, Sichuan Province, China. ${ }^{2}$ University of Electronic Science and Technology of China Hospital, China. ${ }^{3}$ Biotheus Inc, China. ${ }^{4}$ Chengdu Second People's Hospital, Chengdu, Sichuan Province, China. ${ }^{*}$ Correspondence: lijinmei@wchscu.cn.

\#These authors contributed equally to this work.

\section{References}

1. Mathon B, Bédos Ulvin L, Adam C, Baulac M, Dupont S, Navarro V, Cornu P, Clemenceau S: Surgical treatment for mesial temporal lobe epilepsy associated with hippocampal sclerosis. Revue neurologique 2015, 171(3):315-325.

2. Asadi-Pooya A, Stewart G, Abrams D, Sharan A: Prevalence and Incidence of Drug-Resistant Mesial Temporal Lobe Epilepsy in the United States. World neurosurgery 2017, 99:662-666.

3. Uesugi H, Shimizu H, Maehara T, Arai N, Nakayama H: Presence of human herpesvirus 6 and herpes simplex virus detected by polymerase chain reaction in surgical tissue from temporal lobe epileptic patients. Psychiatry and clinical neurosciences 2000, 54(5):589-593.

4. Donati D, Akhyani N, Fogdell-Hahn A, Cermelli C, Cassiani-Ingoni R, Vortmeyer A, Heiss JD, Cogen P, Gaillard WD, Sato $S$ et al: Detection of human herpesvirus-6 in mesial temporal lobe epilepsy surgical brain resections. Neurology 2003, 61(10):1405-1411.

5. Fotheringham J, Williams EL, Akhyani N, Jacobson S: Human herpesvirus 6 (HHV-6) induces dysregulation of glutamate uptake and transporter expression in astrocytes. J Neuroimmune Pharmacol 2008, 3(2):105-116.

6. Eeg-Olofsson O, Bergström T, Andermann F, Andermann E, Olivier A, Rydenhag B: Herpesviral DNA in brain tissue from patients with temporal lobe epilepsy. Acta neurologica Scandinavica 2004, 109(3):169-174. 
7. Theodore WH, Epstein L, Gaillard WD, Shinnar S, Wainwright MS, Jacobson S: Human herpes virus 6B: a possible role in epilepsy? Epilepsia 2008, 49(11):1828-1837.

8. Karatas H, Gurer G, Pinar A, Soylemezoglu F, Tezel G, Hascelik G, Akalan N, Tuncer S, Ciger A, Saygi S: Investigation of HSV-1, HSV-2, CMV, HHV-6 and HHV-8 DNA by real-time PCR in surgical resection materials of epilepsy patients with mesial temporal lobe sclerosis. Journal of the neurological sciences 2008, 264:151-156.

9. Wipfler P, Dunn N, Beiki O, Trinka E, Fogdell-Hahn A: The Viral Hypothesis of Mesial Temporal Lobe Epilepsy - Is Human Herpes Virus- 6 the Missing Link? A systematic review and meta-analysis. Seizure 2018, 54:33-40.

10. Komaroff A, Pellett P, Jacobson S: Human Herpesviruses 6A and 6B in Brain Diseases: Association versus Causation. Clinical microbiology reviews 2020, 34(1).

11. Esposito L, Drexler JF, Braganza O, Doberentz E, Grote A, Widman G, Drosten C, Eis-Hubinger AM, Schoch S, Elger CE et al: Large-scale analysis of viral nucleic acid spectrum in temporal lobe epilepsy biopsies. Epilepsia 2015, 56(2):234-243.

12. Akinsoji E, Leibovitch E, Billioux B, Abath Neto O, Ray-Chaudhury A, Inati S, Zaghloul K, Heiss J, Jacobson S, Theodore W: HHV-6 and hippocampal volume in patients with mesial temporal sclerosis. Annals of clinical and translational neurology 2020, 7(9):1674-1680.

13. Niehusmann P, Mittelstaedt T, Bien CG, Drexler JF, Grote A, Schoch S, Becker AJ: Presence of human herpes virus 6 DNA exclusively in temporal lobe epilepsy brain tissue of patients with history of encephalitis. Epilepsia 2010, 51(12):2478-2483.

14. Opsahl M, Kennedy P: Early and late HHV-6 gene transcripts in multiple sclerosis lesions and normal appearing white matter. Brain : a journal of neurology 2005, 128:516-527.

15. Ichiyama T, Ito Y, Kubota M, Yamazaki T, Nakamura K, Furukawa S: Serum and cerebrospinal fluid levels of cytokines in acute encephalopathy associated with human herpesvirus- 6 infection. Brain \& development 2009, 31(10):731-738.

16. Kawabe S, Ito Y, Ohta R, Sofue A, Gotoh K, Morishima T, Kimura H: Comparison of the levels of human herpesvirus 6 (HHV-6) DNA and cytokines in the cerebrospinal fluid and serum of children with HHV-6 encephalopathy. Journal of medical virology 2010, 82(8):1410-1415.

17. Yoshikawa T, Asano Y, Akimoto S, Ozaki T, Iwasaki T, Kurata T, Goshima F, Nishiyama Y: Latent infection of human herpesvirus 6 in astrocytoma cell line and alteration of cytokine synthesis. Journal of medical virology 2002, 66(4):497-505.

18. Meeuwsen S, Persoon-Deen C, Bsibsi M, Bajramovic J, Ravid R, De Bolle L, van Noort J: Modulation of the cytokine network in human adult astrocytes by human herpesvirus-6A. Journal of neuroimmunology 2005, 164:37-47.

19. Shorvon S: The etiologic classification of epilepsy. Epilepsia 2011, 52(6):1052-1057.

20. Li JM, Lei D, Peng F, Zeng YJ, Li LA, Xia ZL, Xia XQ, Zhou D: Detection of human herpes virus 6B in patients with mesial temporal lobe epilepsy in West China and the possible association with elevated NF-kappa B expression. Epilepsy research 2011, 94(1-2):1-9. 
21. Kawamura Y, Nakayama A, Kato T, Miura H, Ishihara N, Ihira M, Takahashi Y, Matsuda K, Yoshikawa T: Pathogenic Role of Human Herpesvirus 6B Infection in Mesial Temporal Lobe Epilepsy. J Infect Dis 2015, 212(7):1014-1021.

22. Leibovitch EC, Jacobson S: Human Herpesvirus 6 as a Viral Trigger in Mesial Temporal Lobe Epilepsy. J Infect Dis 2015, 212(7):1011-1013.

23. Chang C, Balachandran N: Identification, characterization, and sequence analysis of a cDNA encoding a phosphoprotein of human herpesvirus 6. Journal of virology 1991, 65(6):2884-2894.

24. Ichiyama T, Ito Y, Kubota M, Yamazaki T, Nakamura K, Furukawa S: Serum and cerebrospinal fluid levels of cytokines in acute encephalopathy associated with human herpesvirus- 6 infection. Brain \& development 2009, 31(10):731-738.

25. Agulnick A, Thompson J, lyengar S, Pearson G, Ablashi D, Ricciardi R: Identification of a DNA-binding protein of human herpesvirus 6, a putative DNA polymerase stimulatory factor. The Journal of general virology 1993:1003-1009.

26. Agulnick AD, Thompson JR, lyengar S, Pearson G, Ablashi D, Ricciardi RP: Identification of a DNAbinding protein of human herpesvirus 6, a putative DNA polymerase stimulatory factor. The Journal of general virology 1993, 74 (Pt 6):1003-1009.

27. Ahlqvist J, Fotheringham J, Akhyani N, Yao K, Fogdell-Hahn A, Jacobson S: Differential tropism of human herpesvirus 6 (HHV-6) variants and induction of latency by HHV-6A in oligodendrocytes. Journal of neurovirology 2005, 11(4):384-394.

28. Rotola A, Ravaioli T, Gonelli A, Dewhurst S, Cassai E, Di Luca D: U94 of human herpesvirus 6 is expressed in latently infected peripheral blood mononuclear cells and blocks viral gene expression in transformed lymphocytes in culture. Proceedings of the National Academy of Sciences of the United States of America 1998, 95(23):13911-13916.

29. Trempe F, Gravel A, Dubuc I, Wallaschek N, Collin V, Gilbert-Girard S, Morissette G, Kaufer B, Flamand L: Characterization of human herpesvirus 6A/B U94 as ATPase, helicase, exonuclease and DNAbinding proteins. Nucleic acids research 2015, 43(12):6084-6098.

30. Caselli E, Bracci A, Galvan M, Boni M, Rotola A, Bergamini C, Cermelli C, Dal Monte P, Gompels UA, Cassai E et al: Human herpesvirus 6 (HHV-6) U94/REP protein inhibits betaherpesvirus replication. Virology 2006, 346(2):402-414.

31. Caselli E, D'Accolti M, Caccuri F, Soffritti I, Gentili V, Bortolotti D, Rotola A, Cassai E, Fiorentini S, Zani A et al: The U94 Gene of Human Herpesvirus 6: A Narrative Review of Its Role and Potential Functions. Cells 2020, 9(12).

32. Wallaschek N, Gravel A, Flamand L, Kaufer B: The putative U94 integrase is dispensable for human herpesvirus 6 (HHV-6) chromosomal integration. The Journal of general virology 2016, 97(8):18991903.

33. Fotheringham J, Donati D, Akhyani N, Fogdell-Hahn A, Vortmeyer A, Heiss JD, Williams E, Weinstein S, Bruce DA, Gaillard WD et al: Association of human herpesvirus-6B with mesial temporal lobe epilepsy. PLoS Med 2007, 4(5):e180. 
34. Yao K, Honarmand S, Espinosa A, Akhyani N, Glaser C, Jacobson S: Detection of human herpesvirus6 in cerebrospinal fluid of patients with encephalitis. Annals of neurology 2009, 65(3):257-267.

35. Kawamura Y, Sugata K, Ihira M, Mihara T, Mutoh T, Asano Y, Yoshikawa T: Different characteristics of human herpesvirus 6 encephalitis between primary infection and viral reactivation. Journal of clinical virology : the official publication of the Pan American Society for Clinical Virology 2011, 51(1):12-19.

36. Kawabe S, Ito Y, Ohta R, Sofue A, Gotoh K, Morishima T, Kimura H: Comparison of the levels of human herpesvirus 6 (HHV-6) DNA and cytokines in the cerebrospinal fluid and serum of children with HHV-6 encephalopathy. Journal of medical virology 2010, 82(8):1410-1415.

37. Perlejewski K, Bukowska-Ośko I, Rydzanicz M, Dzieciątkowski T, Zakrzewska-Pniewska B, PodleckaPiętowska A, Filipiak A, Barć K, Caraballo Cortés K, Pawełczyk A et al: Search for viral agents in cerebrospinal fluid in patients with multiple sclerosis using real-time PCR and metagenomics. PloS one 2020, 15(10):e0240601.

38. Alvarez-Lafuente R, De las Heras V, Bartolomé M, Picazo J, Arroyo R: Relapsing-remitting multiple sclerosis and human herpesvirus 6 active infection. Archives of neurology 2004, 61(10):1523-1527.

\section{Tables}

Table 1: Clinical features of the patients with refractory MTLE epilepsy 


\begin{tabular}{|ll|}
\hline Total & Number or mean value \pm SD (range) \\
\hline Male/Female & $20 / 29$ \\
\hline Mean age at surgery $(\mathrm{yr})$ & $26.73 \rrbracket \pm 11.11 \llbracket \mathrm{S}(15-55)$ \\
\hline Duration of seizure $(\mathrm{yr})$ & $10.36 \pm 6.51(3-32)$ \\
\hline History of febrile seizure & $13(26.53 \%)$ \\
\hline Seizure type & \\
\hline CPS/SGS/GTCS/MT/SE & $14 / 32 / 0 / 3 / 0$ \\
\hline Frequency of seizure attack per month & $20.5 \pm 7.6(1-60)$ \\
\hline One/Two/more AEDs & $21 / 14 / 22$ \\
\hline MRI & \\
\hline HS/NAF & $44 / 5$ \\
\hline Video EEG & \\
\hline SP/NSP & $49 / 0$ \\
\hline Resection field & \\
\hline TN+HI/TN+Hr & $23 / 26$ \\
\hline Pathologic results* & \\
\hline HS Type1/Type2/Type3/NAF & $35 / 5 / 5 / 4$ \\
\hline
\end{tabular}

CPS, Complex Partial Seizure, SGS, Secondary Generalized Seizure,GTCS, Generalized Tonic-Clonic Seizure, MT, Multiple Type including tonic-clonic, tonic, clonic and complex partial seizures, SE, status epilepticus, AEDs including Phenytoin, Phenobatital, Valproic acid, Carbamazepine, Topiramate, Lamotrigine and Clonazepam, HS, hippocampus sclerosis, NAF, No Abnormal Findings, SP, spikes, NSP, no spikes, TN, Temporal Neocortex, H, hippocampus, I, left, r, right.

*According to 2013 ILAE pathological classification of hippocampal sclerosis in temporal lobe epilepsy.

Table 2: Clinical features of the control cases 


\begin{tabular}{|ll|}
\hline Total & Number or mean value \pm SD (range) \\
\hline Male/Female & $10 / 9$ \\
\hline Mean age $(\mathrm{yr})$ & $32.52 \pm 8.15(15-61)$ \\
\hline Cause for admission & \\
\hline Trauma/Cerebral hemorrhage & $12 / 7$ \\
\hline Resection tissue & \\
\hline HI/Hr/TNI+ HI/TNr+Hr & $5 / 5 / 4 / 5$ \\
\hline Tissue pathological findings & \\
\hline NAF & 19 \\
\hline
\end{tabular}

TN, Temporal Neocortex, H, hippocampus, L, left, r, right, NAF, No abnormal findings.

\section{Figures}

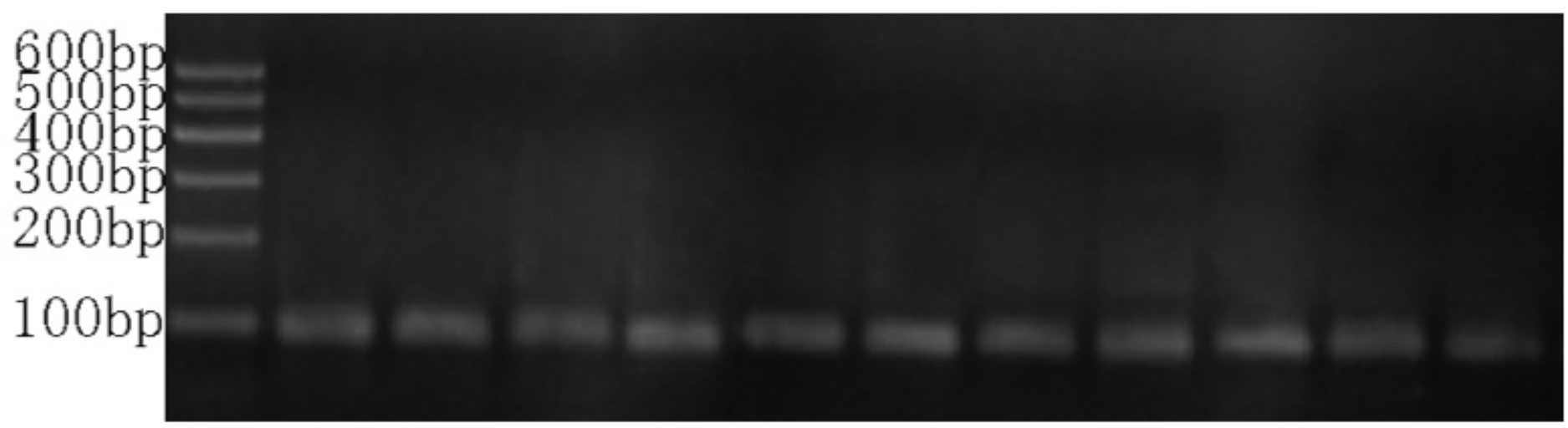

\section{Figure 1}

The presence of HHV-6B DNA in brain tissue from MTLE patients: Agarosegel electrophoresis of representative PCR amplification products from brain tissue. The HHV-6B amplification product was $119 \mathrm{bp}$. 

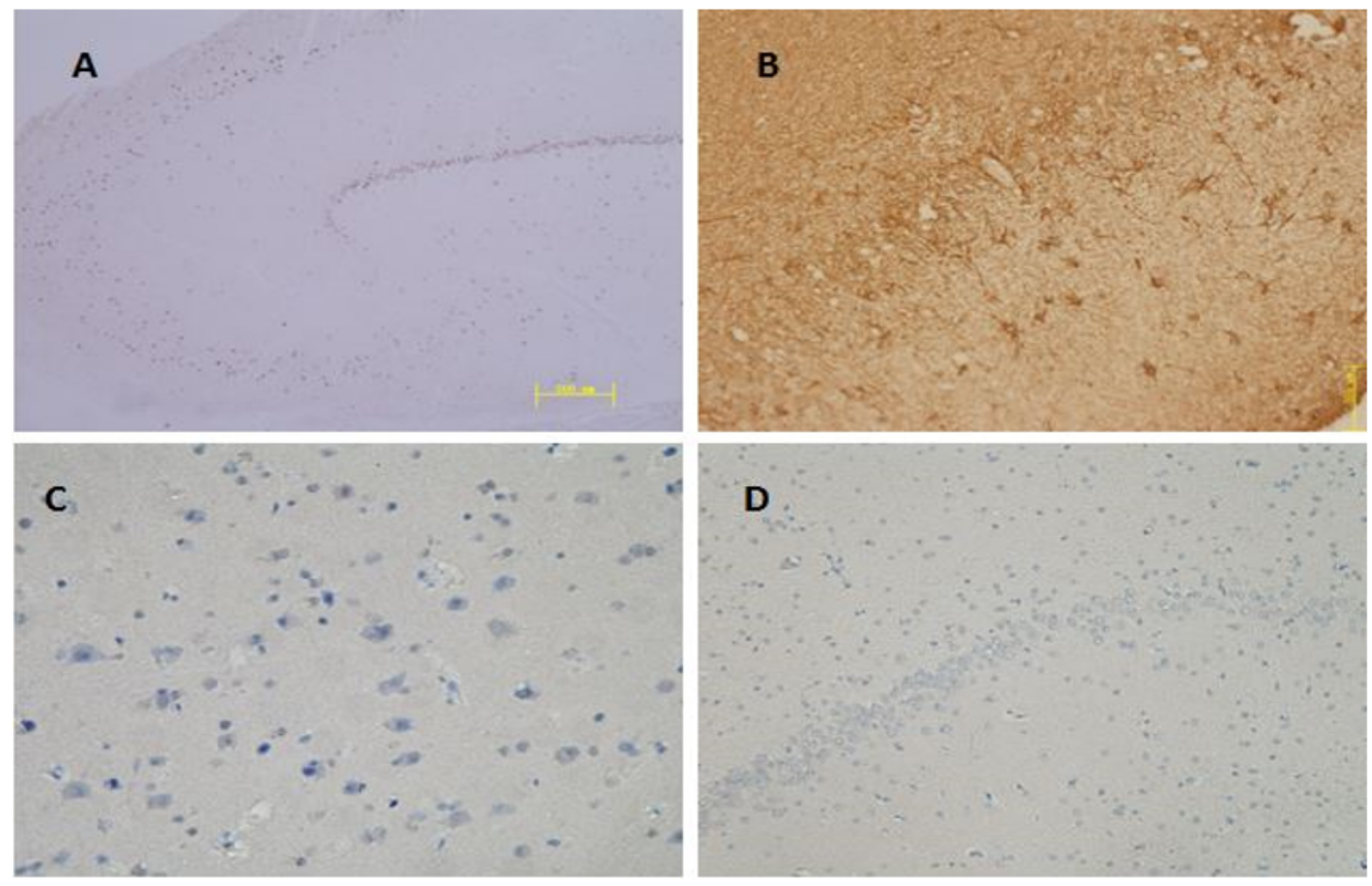

\section{Figure 2}

Pathological finding and detection of CD3 and CD4 in adult MTLE by immunohistochemistry. IHC with antibodies against NeuN (A) and GFAP (B) revealed a typical pattern of a MTS with distinctive neuron loss in CA4, CA3 and CA1 regions. Negative staining of CD3 (C) and CD4 (D) shows no lymphocytic infiltration in brain samples. 

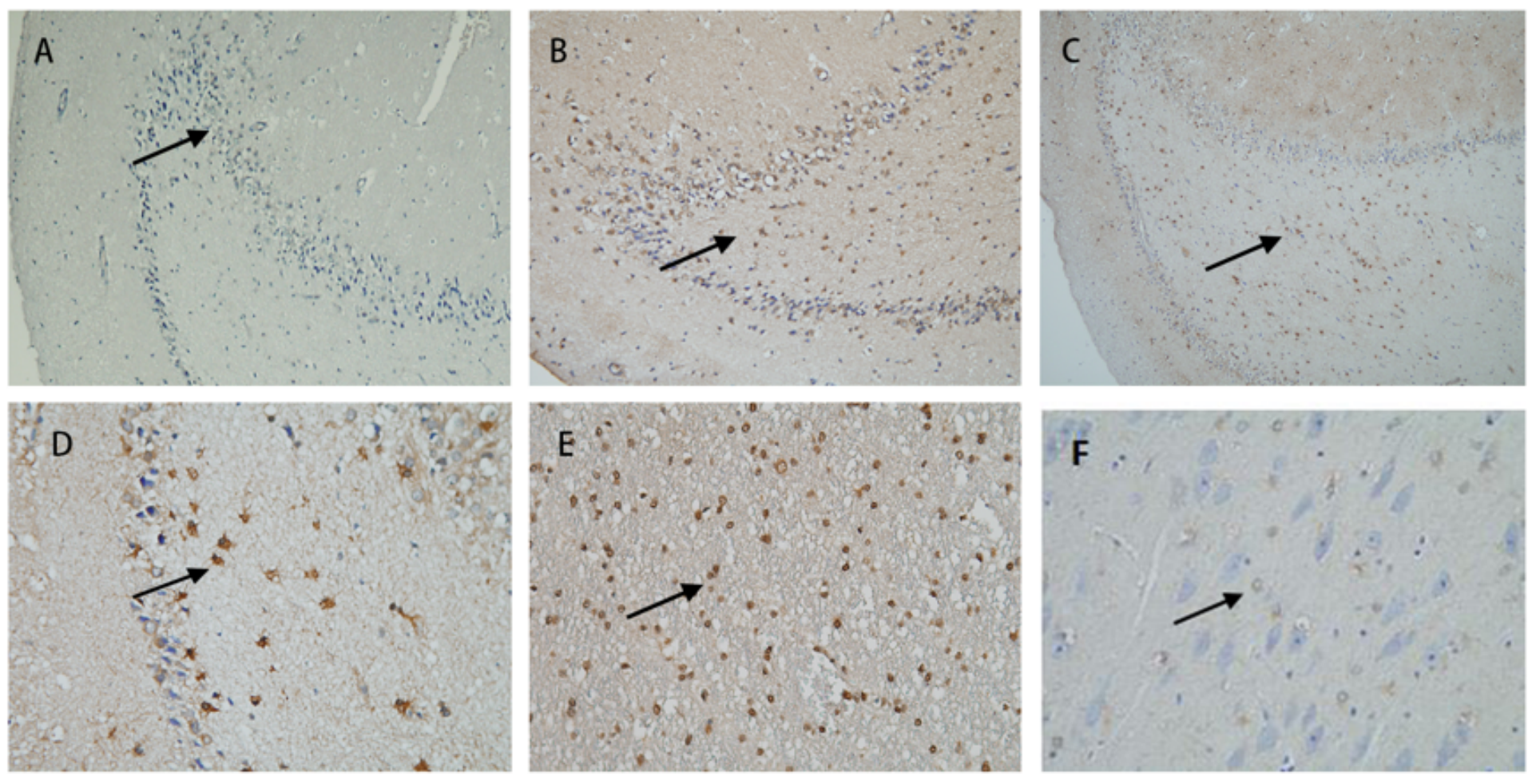

\section{Figure 3}

Detection of HHV-6B latent early and late antigen in adult MTLE by immunohistochemistry. Detection of HHV-6B of Gp116 immunoreactivity present around nucleusof glial cells (A) in an individual, The same patient also showed P41 positivity (B) and U94 positivity (C). An individual only with Gp116 positivity in dentate gyrus and vacuoles was seen the interstitial substance (D). An individual with only with P41 positivity shows immunoreactivity present in nuclear of glial cells (E). An indivadual only with U94 positivity shows strong immunoreactivity in dentate gyrus $(F)$. 


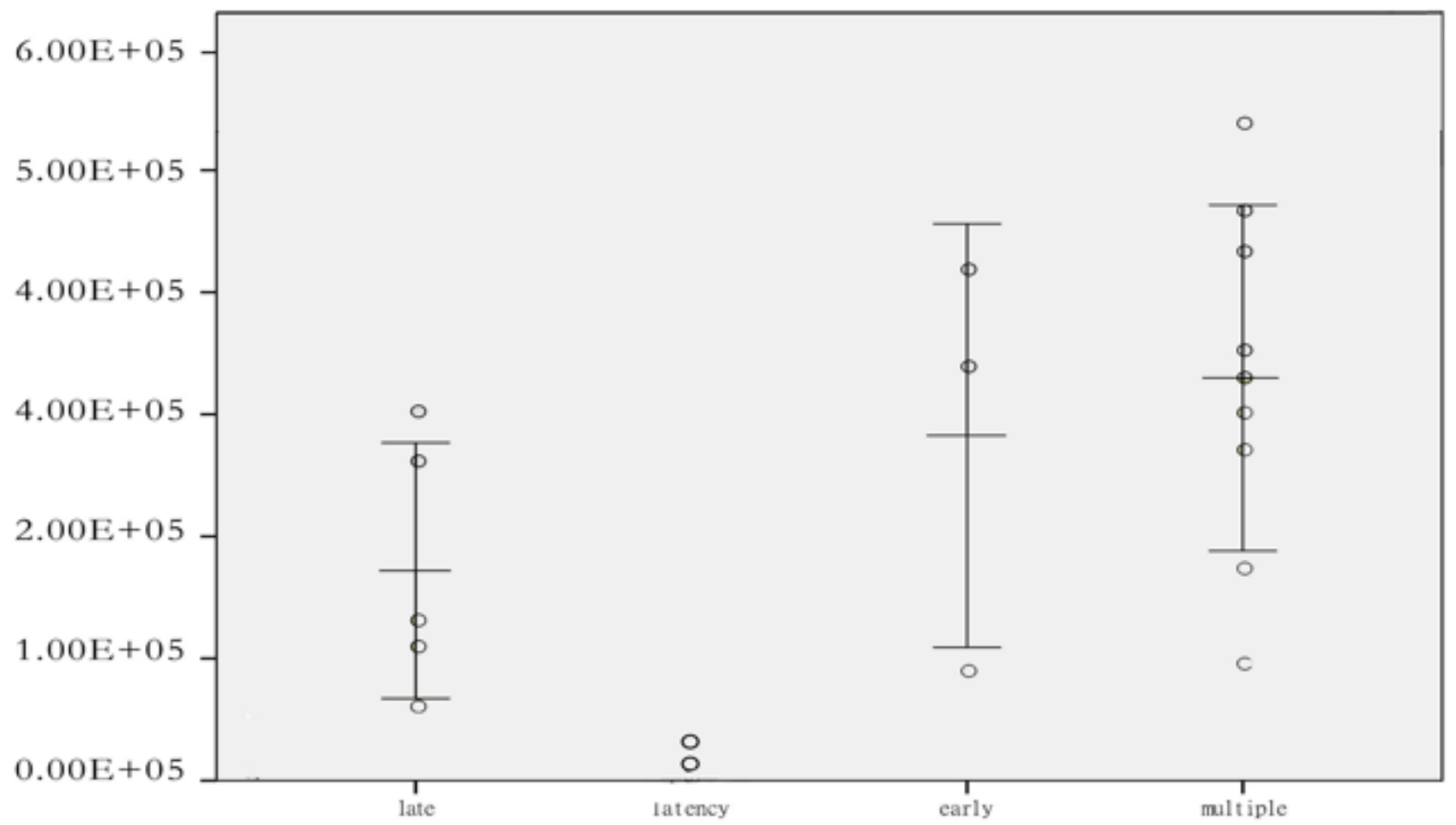

\section{Figure 4}

HHV-6B DNA Load in different subgroups in 19 cases with positive PCR results for HHV-6B DNA.(Each circle represents a sample, plotted by virus states on the horizontal axis and viral load on the vertical, viral load $/ 10^{\wedge} 6$ cells) 


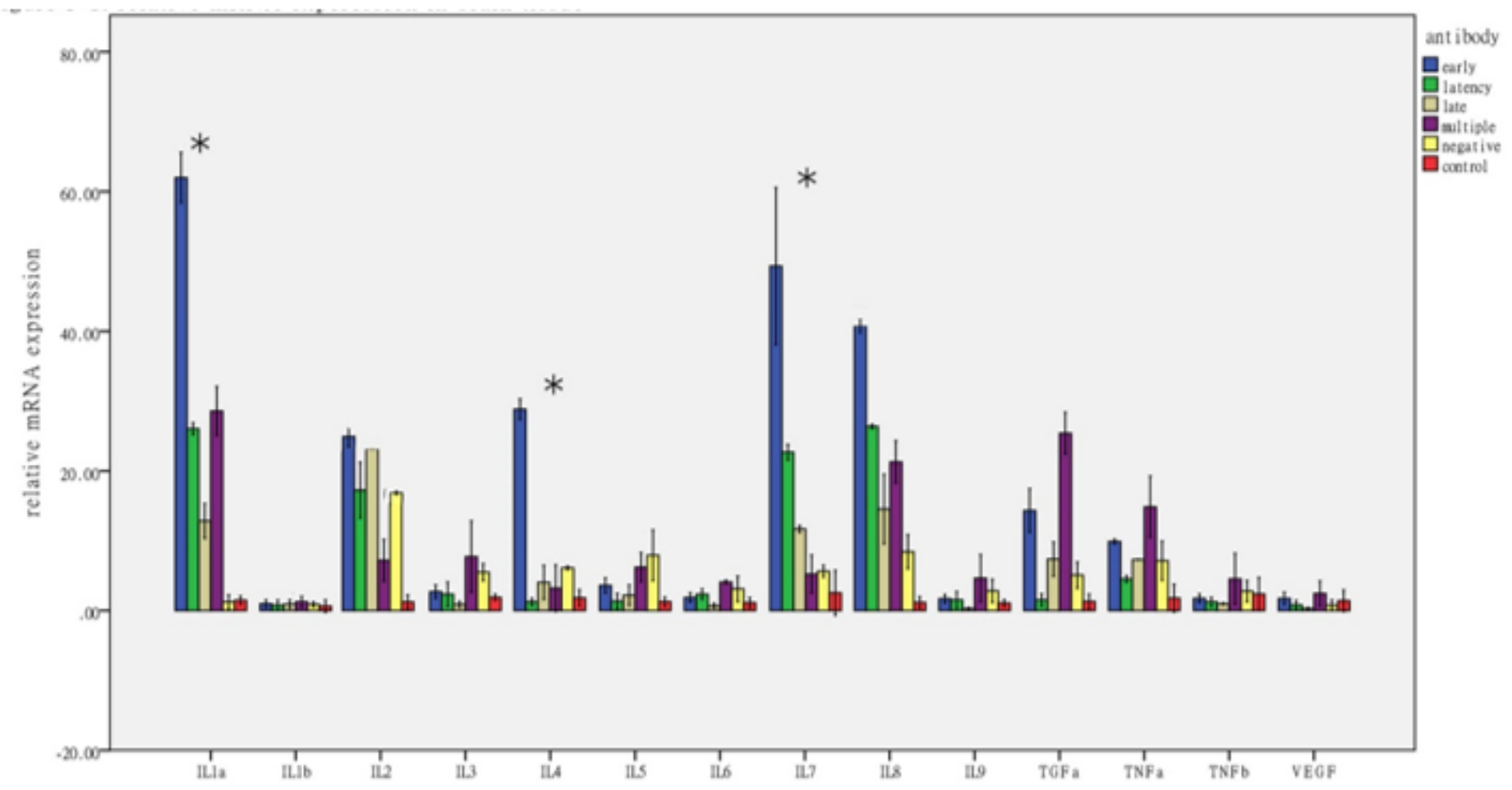

Figure 5

The post hoc tests result of cytokines mRNA levels in brain tissue showing significant difference of IL-1a, IL-2 and IL-7 in different groups. 


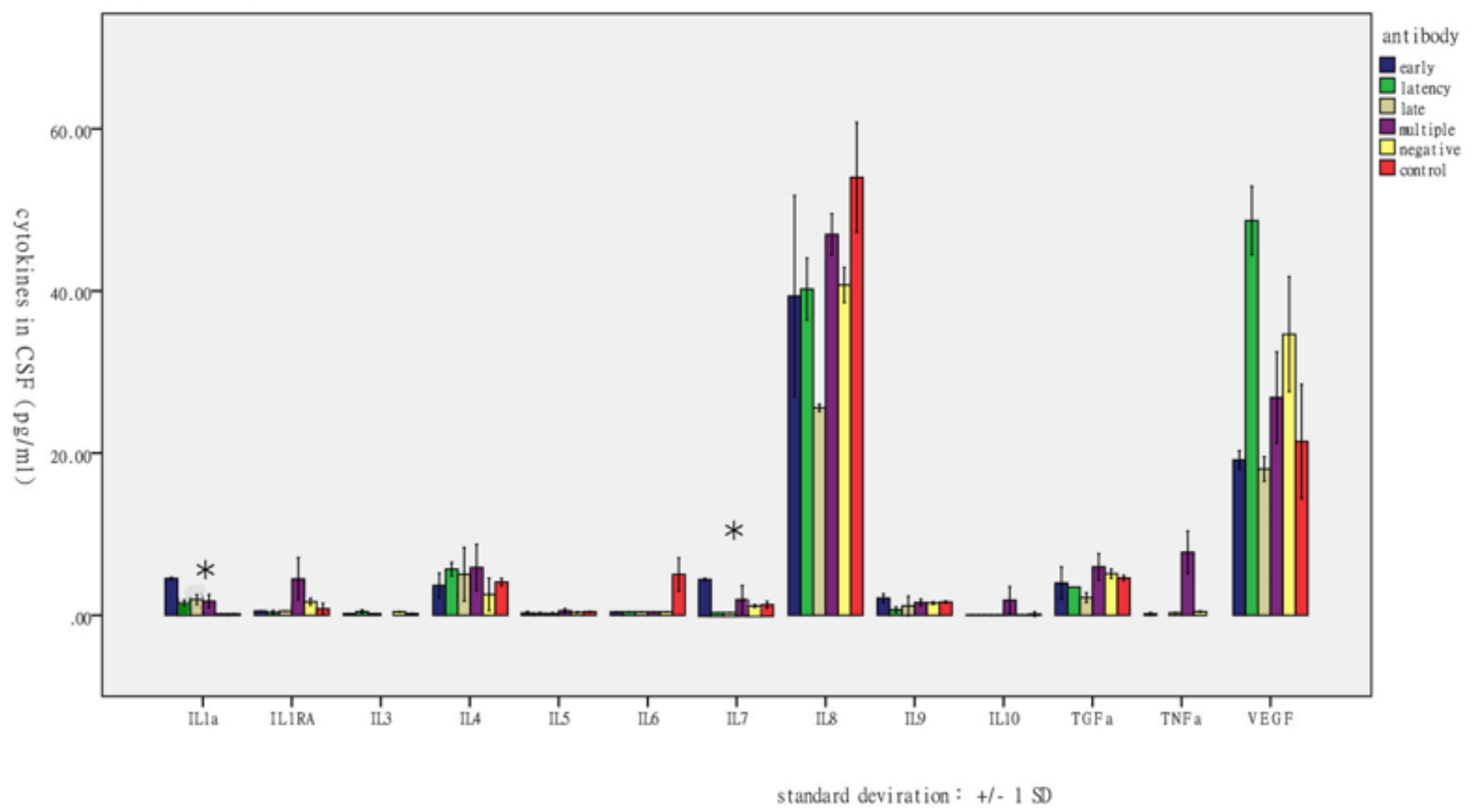

Figure 6

The post hoc tests result of cytokines protein levels in CSF by cytometric bead array showing significant difference of IL-1a, IL-2 and IL-7 in different groups.

\section{Supplementary Files}

This is a list of supplementary files associated with this preprint. Click to download.

- SupplementalTable1.docx 